\title{
Centralized Pan-Middle East Survey on the Under- Treatment of Hypercholesterolemia: Results from the CEPHEUS Study in Egypt
}

\author{
A. Reda • A. A. Abdel-Rehim • A. Etman • O. S. A. Afifi
}

To view enhanced content go to www.cardiologytherapy-open.com

Received: September 18, 2014 / Published online: November 18, 2014

(c) The Author(s) 2014. This article is published with open access at Springerlink.com

\section{ABSTRACT}

Background: Cardiovascular disease is a major cause of morbidity and mortality; however, the risks associated with this disease can be reduced by targeting circulating low-density lipoprotein cholesterol (LDL-C) with lipid-lowering drugs, as recommended in many treatment guidelines. Their effectiveness for hypercholesterolemia

Trial registration: ClinicalTrials.gov Identifier: NCT01604733, NIS-EG-CRE-2012/01.

Electronic supplementary material The online version of this article (doi:10.1007/s40119-014-0031-x) contains supplementary material, which is available to authorized users.

A. Reda $(\square)$

College of Medicine, Menoufiya University, Shebin El-Kom, Egypt

e-mail: ashrafreda5555@gmail.com

A. A. Abdel-Rehim

Diabetes and Metabolism Unit, Alexandria

University, Alexandria, Egypt

A. Etman

Department of Internal Medicine, Ain Shams

University, Cairo, Egypt

O. S. A. Afifi

Cardiology Department, Banha University, Banha, Egypt management depends on appropriate use in at-risk patients. Observational studies have shown varying adherence to national and international guidelines on reaching LDL-C treatment goals.

Methods: The Centralized Pan-Middle East Survey on the under-treatment of hypercholesterolemia (CEPHEUS) study observed the current management of hypercholesterolemia in patients on lipidlowering drugs in seven Middle Eastern countries, and results from 1,043 patients in Egypt are presented here.

Results: Overall, less than 50\% of patients achieved their LDL-C treatment goal, with patients at higher risk of a cardiovascular event being less likely to attain their target. Nearly, three-quarters of patients in this study were considered high or very high risk, with only $10 \%$ of high-risk patients reaching their treatment goal.

Conclusions: Management of hypercholesterolemia in Egypt is comparatively worse than the average for similar countries in the region, and many patients with high risk of CVD are not being effectively treated. Initiatives to improve 
physicians' management of these patients and patient compliance to treatment are urgently needed.

Funding: AstraZeneca, Cairo, Egypt.

Keywords: Cardiovascular

disease; Cardiovascular risk; CEPHEUS; Egypt; Hypercholesterolemia; LDL cholesterol; Lipidlowering drugs; Low-density lipoprotein cholesterol; Observational; Statins

\section{INTRODUCTION}

Cardiovascular disease (CVD) is the most common cause of death worldwide, accounting for an estimated 17.3 million deaths in 2008 and representing 30\% of all global deaths [1]. The World Health Organization projects that CVD will remain the leading cause of death worldwide in future years, with deaths from CVD estimated to increase to 23.3 million by $2030[1,2]$.

Currently, over $80 \%$ of CVD deaths occur in low- and middle-income countries [1]. This has been attributed to the fact that people in these countries are typically exposed to more risk factors, such as tobacco and dyslipidemia [high apolipoprotein B (ApoB):apolipoprotein A1 (ApoA1) ratio] [3]. In addition, they are likely to have less access to early detection and prevention programs than patients in more developed countries [3]. These factors also contribute to the fact that the mean age [ \pm standard deviation (SD)] of first presentation of acute myocardial infarction (AMI) has been observed to be $51.2( \pm 10.3)$ years in Middle Eastern countries, approximately 10 years younger than in other regions of the world [3, 4]. Furthermore, the Middle East has the highest proportion of first AMI in individuals aged 40 years or younger [4].
In Egypt, the age-standardized annual death rate from CVD is over 400 per 100,000 population, and this compares to rates of less than 150 per 100,000 population in some European countries [5]. The Egyptian National Hypertension Project, which surveyed over 6,700 subjects, reported the national incidence of coronary heart disease to be $8.3 \%$ [5]. The incidence was higher in women than men ( $8.9 \%$ versus $8.0 \%$, respectively) and higher in urban populations than rural populations $(8.8 \%$ versus $7.2 \%$, respectively).

There is epidemiological evidence that elevated total serum cholesterol, specifically elevated levels of low-density lipoprotein cholesterol (LDL-C), is strongly correlated with the risk of coronary heart disease [6-10]. Thus, a principal intervention to reduce the risk of cardiovascular events in patients with CVD is to control the level of circulating lipids, particularly LDL-C $[8,11,12]$. Clinical intervention studies have shown that the impact of lipid-lowering treatment is primarily dependent on the individual's baseline risk of a cardiovascular event, and that the reduction in risk of an event subsequently occurring is proportional to the degree of LDL-C lowering achieved by treatment $[8,11-13]$. Therefore, since the late 1980s, guidelines for the prevention of CVD have recommended treatment goals based on reducing the baseline risk of the patient. The US National Cholesterol Education Program Adult Treatment Panel III guidelines (NCEP ATP III) on cholesterol management, originally produced in 2002 [10], were updated in 2004 [14] to reflect the findings of major clinical trials that confirmed the benefits of lipid-lowering therapy in highrisk, diabetic and elderly patients.

With the introduction of more stringent guidelines and the widespread increased use of lipid-lowering therapy, there is a need to 
evaluate the current level of under-treatment of hypercholesterolemia. It is also important to understand why patients being actively treated with lipid-lowering drugs do not achieve their treatment goal. The Centralized Pan-Middle East survey on the under-treatment of hypercholesterolemia (CEPHEUS) assessed the current management of hypercholesterolemia in patients on lipid-lowering drugs in Middle Eastern countries [Bahrain, Egypt, Oman, Qatar, the United Arab Emirates (UAE), the Kingdom of Saudi Arabia (KSA) and Kuwait]. The primary aim of this study was to establish the proportion of patients on lipid-lowering pharmacological treatment who attained their LDL-C treatment goal, as defined by NCEP ATP III 2002 and 2004 guidelines. Secondary endpoints included: evaluation of the proportion of patients in pre-defined sub-populations achieving their LDL-C treatment goal, identification of determinants (patient and physician characteristics) for patients not reaching their treatment goal and physician characteristics associated with the allocation of different treatment regimens. The results reported here are for the Egyptian arm of this study, which was conducted in Cairo and Alexandria.

\section{METHODS}

\section{Study Design}

This was a multicenter, observational study of patients receiving lipid-lowering pharmacological treatment in Cairo and Alexandria, Egypt, conducted in 2010 and 2011 as part of the CEPHEUS study (clinicaltrials.gov identifiers: NCT01604733, NIS-EG-CRE-2012/01). All procedures followed were in accordance with the ethical standards of the responsible committee on human experimentation (institutional and national) and with the Helsinki Declaration of 1975, as revised in 2000 and 2008, and are consistent with the International Conference on Harmonisation/Good Clinical Practice (ICHGCP). Informed consent was obtained from all patients for being included in the study.

\section{Study Objectives}

The primary objective of the study was to establish the proportion of patients receiving lipid-lowering pharmacological treatment who reach their LDL-C goals, according to the NCEP ATP III/NCEP ATP III 2004 updated guidelines $[10,14]$. These guidelines recommend a therapeutic LDL-C goal of $<100 \mathrm{mg} / \mathrm{dL}$ for those at high risk of cardiovascular events (10year risk $>20 \%$ of coronary heart disease), with an option to further lower the goal to $<70 \mathrm{mg} /$ $\mathrm{dL}$ for individuals at very high risk (established coronary heart disease and multiple major risk factors, severe and persistent risk factors, metabolic syndrome or acute coronary syndrome). The recommended LDL-C goal for those at moderately high risk (two or more risk factors and a 10-year risk of 10-20\%) is $<130 \mathrm{mg} / \mathrm{dL}$ [14]. For patients considered at low risk, non-pharmacological intervention such as changes in diet, smoking cessation and an increase in exercise are generally recommended. For patients at a higher risk, lipid-lowering drugs, e.g., statins, fibrates or cholesterol absorption inhibitors, are recommended.

Key secondary objectives were to establish the proportion of patients achieving their treatment goals and the proportion of patients achieving their target goals in the following sub-populations: primary/secondary prevention patients and patients with metabolic syndrome (defined according to NCEP ATP III). Other 
secondary goals were: to establish the proportion of patients on lipid-lowering pharmacological treatment reaching the nonhigh-density lipoprotein cholesterol (HDL-C) goals according to the NCEP ATP III/NCEP ATP III 2004 updated guidelines $(<130 \mathrm{mg} / \mathrm{dL})$ in the sub-population of patients with fasting triglycerides $>200 \mathrm{mg} / \mathrm{dL}$; to identify determinants (e.g., patient and physician characteristics, country-specific guidelines or recommendations) for under-treatment of hypercholesterolemia; and to explore physician characteristics associated with the allocation of different treatment regimens. NCEP ATP III 2004 updated guidelines and goals were used to evaluate management efficacy because they were the most commonly used at the time of study.

\section{Study Inclusion Criteria}

Subjects fulfilling the following inclusion criteria were enrolled in the study: age $\geq 18$ years; receiving lipid-lowering drug treatment for at least 3 months with no dose change for at least 6 weeks; and provision of written informed consent to participate in the study and comply with study procedures.

\section{Study Procedures}

The study planned to enroll 1,100 randomly selected patients being treated by 78 specialists and primary care physicians located in Cairo and Alexandria, Egypt. The required sample size was calculated to ensure that the primary and secondary endpoints could be estimated with sufficient precision to represent the heterogeneity of this population, and was based on an estimated 50\% of participants being expected to achieve their treatment goal.
Prior to assessing their first study participant, each investigator was required to complete a questionnaire on their experience and perception of the management of hypercholesterolemia observed in their patients. Consecutive patients who came for a regularly scheduled visit to the clinic were invited to participate in the survey. Each study participant was required to attend a single clinic visit, during which a fasting blood sample was obtained for analysis of total cholesterol, LDLC, HDL-C, triglycerides, glucose, glycosylated hemoglobin (HbA1c) and calculation of the ratio of total cholesterol/HDL cholesterol. Three separate samples were collected from each patient and all samples were analyzed at the accredited central laboratory in Cairo. Participants also underwent a physical examination by the investigator to determine their height, weight, waist circumference and blood pressure. Following the visit, investigators received the laboratory results together with a copy of the NCEP ATP III 2004 updated guidelines [14]. These were supplied to the investigators for educational purposes to enable them to take any appropriate measures regarding the future treatment of the patient.

Prior to attendance at the clinic, participants were required to complete a questionnaire relating to their awareness of hypercholesterolemia, their current treatment schedule, treatment goals, satisfaction with treatment and their compliance to treatment. Investigators also completed a patient record form for each participant, detailing the patient's demographics, known cardiovascular risk factors, cardiovascular medical history, current lipid-lowering drug treatment and rationale for their current treatment. Each subject had their risk category according to NCEP ATP III 2004 updated guidelines determined programmatically by an expert panel. 
Table 1 Patient demographics and clinical characteristics

\begin{tabular}{|c|c|}
\hline Variable & Value \\
\hline Age, years, mean $(\mathrm{SD})$ & $57.73(11.20)$ \\
\hline Male, $n(\%)$ & $525(50.30)$ \\
\hline Female, $n(\%)$ & $518(49.70)$ \\
\hline \multicolumn{2}{|l|}{ Blood pressure, mm Hg (SD) } \\
\hline Mean systolic & $135.55(17.28)$ \\
\hline Mean diastolic & $84.82(9.96)$ \\
\hline Body weight, kg, mean (range) & $89.2(48.00-170.00)$ \\
\hline Waist circumference, $\mathrm{cm}$, mean (range) & $105.39(60.00-180.00)$ \\
\hline Body mass index, $\mathrm{kg} / \mathrm{m}^{2}$, mean (range) & $31.83(17.10-69.20)$ \\
\hline History of coronary heart disease, $n(\%)$ & $431(41.30)$ \\
\hline History of cerebrovascular disease, $n(\%)$ & $117(11.20)$ \\
\hline History of peripheral arterial disease, $n$ (\%) & $75(7.20)$ \\
\hline Family history of premature cardiovascular disease, $n$ (\%) & $373(35.80)$ \\
\hline \multicolumn{2}{|l|}{ Comorbidities, $n$ (\%) } \\
\hline Diabetes & $506(48.50)$ \\
\hline Arterial hypertension & $739(70.80)$ \\
\hline Current smoker, $n$ (\%) & $197(18.90)$ \\
\hline \multicolumn{2}{|l|}{ Reason for pharmacological therapy, $n$ (\%) } \\
\hline Primary prevention & $630(60.40)$ \\
\hline Secondary prevention & $374(35.70)$ \\
\hline Familial hypercholesterolemia & $39(3.70)$ \\
\hline \multicolumn{2}{|l|}{ Type of pharmacological therapy, $n(\%)$} \\
\hline Statins & $883(94.20)$ \\
\hline Fibrates & $38(4.00)$ \\
\hline
\end{tabular}

$S D$ standard deviation

\section{Statistical Analysis}

The statistical analysis was of a descriptive nature. Continuous data are described by mean, SD, median, minimum and maximum values. Categorical data are described by the number and percentage of subjects in each category. Missing data were not included in the calculation of proportions. The association between achievement of LDL-C goals and patient/physician variables was analyzed by a multivariate logistic regression model. 


\section{RESULTS}

A total of 1,182 patients were enrolled in this study between 13 October 2010 and 7 June 2011. One hundred and thirty-nine patients were excluded from the analysis due to missing LDL-C data, resulting in data from 1,043 patients being included in the final analysis. The demographics and clinical characteristics of the study cohort are reported in Table 1 . The mean age of participants was 54.73 years, and $50.30 \%$ were male. The main reason for pharmacological treatment was primary prevention $(60.40 \%)$, and statins were the most frequent treatment of choice (94.20\%). The mean laboratory blood values for all variables analyzed in the study are given in Table 2.

Overall, $32.5 \%$ of patients achieved their LDL-C treatment goal according to criteria outlined in the NCEP ATP III 2004 updated guidelines (Table 3). Patients considered to have a low or medium-low risk profile (as determined by NCEP ATP III 2004 updated guidelines criteria) had the highest rate of achieving their

Table 2 Summary of results of laboratory blood analysis of study participants

\begin{tabular}{lll}
\hline Variable & Mean & SD \\
\hline $\begin{array}{l}\text { Total cholesterol, } \\
\mathrm{mg} / \mathrm{dL}(\mathrm{mmol} / \mathrm{L})\end{array}$ & $194.45(5.03)$ & $48.16(1.25)$ \\
LDL-C, mg/dL (mmol/L) & $119.28(3.08)$ & $40.87(1.06)$ \\
HDL-C, mg/dL (mmol/L) & $45.70(1.18)$ & $12.06(0.31)$ \\
$\begin{array}{l}\text { Triglycerides, mg/dL } \\
\text { (mmol/L) }\end{array}$ & $147.04(1.66)$ & $105.06(1.19)$ \\
HbAlc, \% (mmoL/moL) & $7.42(58.00)$ & $1.99(-2.00)$ \\
Glucose, mg/l & 128.31 & 58.31 \\
\hline
\end{tabular}

$H b A l c$ glycosylated hemoglobin, $H D L-C$ high-density lipoprotein cholesterol, $L D L-C$ low-density lipoprotein cholesterol, $S D$ standard deviation
LDL-C treatment goal (Fig. 1; Table 3). Out of 187 subjects with fasting triglycerides $>200 \mathrm{mg}$ / $\mathrm{dL}$ (>2.26 mmol/L), 103 patients (55.10\%) achieved their non-HDL-C treatment goal; it should be noted that information on other drugs that could have affected non-HDL-C levels is not available.

In patients with arterial hypertension, a family history of CVD or metabolic syndrome, 26.0, 30.0 and 26.1\%, respectively, attained their LDL-C treatment goals, as defined by the NCEP ATP III 2004 updated guidelines (Table 4). The proportion of current smokers and patients with diabetes achieving their treatment goals was low at $17.3 \%$ and $20.6 \%$, respectively.

Using the NCEP ATP III 2004 updated guidelines treatment goal criteria, the most effective statins were rosuvastatin, pravastatin and simvastatin, with $39.0,37.5$ and $33.8 \%$ of patients prescribed these medications achieving their LDL-C treatment goals, respectively (Table 3).

\section{Results of the Investigators' Questionnaire}

Seventy-seven of the 78 participating investigators, covering a total of 122 sites, returned a completed questionnaire. Most of the investigators were male (92.2\%) with a mean age of 50.5 years (SD 7.3). The majority of the investigators were cardiologists (55.8\%); $10.4 \%$ were endocrinologists, $29.9 \%$ were other specialists and $3.9 \%$ were primary care physicians.

Most investigators (76.0\%) stated that they used guidelines to establish the individual target cholesterol levels of patients, with over half of these using the NCEP ATP III 2004 updated guidelines. Additional data from the investigators' questionnaire is presented in Table 5. 
Table 3 Patient baseline risk category according to the NCEP ATP III 2004 updated guidelines; the number of patients in each risk category obtaining their treatment goals, overall and according to statin prescribed

\begin{tabular}{|c|c|c|c|c|c|}
\hline Patient characteristics & $\begin{array}{l}\text { Risk } \\
\text { category }\end{array}$ & LDL-C target & $\begin{array}{l}\text { Number of } \\
\text { patients at } \\
\text { baseline, } \\
n(\%)\end{array}$ & $\begin{array}{l}\text { Patients } \\
\text { achieving } \\
\text { treatment } \\
\text { goal, } n(\%)\end{array}$ & $\begin{array}{l}\text { Patients achieving } \\
\text { treatment goal according } \\
\text { to prescribed statin, } n(\%) \\
{[\text { mean dose, } \mathrm{mg} \pm \mathrm{SD}]}\end{array}$ \\
\hline All patients & All & & & $339(32.5)$ & $\begin{array}{l}\text { Atorvastatin: } 135(28.1) \\
\quad[17.6 \pm 10.2] \\
\text { Simvastatin: } 46(33.8) \\
{[22.0 \pm 11.1]} \\
\text { Rosuvastatin: } 135(39.0) \\
\quad[13.3 \pm 4.7] \\
\text { Fluvastatin:4 (20.0) [NA] } \\
\text { Pravastatin:3 (37.5) [NA] }\end{array}$ \\
\hline $\begin{array}{l}\text { Established CVD plus diabetes, } \\
\text { smoker, low HDL-C and high } \\
\text { triglycerides, metabolic syndrome } \\
\text { or multiple risk factors (see } \\
\text { definition below) }\end{array}$ & $\begin{array}{l}\text { Very } \\
\text { high }\end{array}$ & $\begin{array}{l}<70 \mathrm{mg} / \mathrm{dL} \\
\quad(1.81 \mathrm{mmol} / \mathrm{L})\end{array}$ & $393(37.7)$ & $42(10.7)$ & $\begin{array}{l}\text { Rosuvastatin: } 14(11.4) \\
{[\mathrm{NA}]} \\
\text { Atorvastatin: } 21(10.4)[\mathrm{NA}] \\
\text { Simvastatin: } 4(8.9)[\mathrm{NA}]\end{array}$ \\
\hline $\begin{array}{l}\text { CHD, or CHD risk equivalents, or } \\
\text { Framingham } 10 \text {-year risk }>20 \%\end{array}$ & High & $\begin{array}{l}<100 \mathrm{mg} / \mathrm{dL} \\
\quad(2.59 \mathrm{mmol} / \mathrm{L})\end{array}$ & $362(34.7)$ & $124(34.2)$ & $\begin{array}{l}\text { Rosuvastatin: } 46(49.0) \\
\quad[\mathrm{NA}] \\
\text { Atorvastatin: } 53(40.0)[\mathrm{NA}] \\
\text { Simvastatin: } 20(45.6)[\mathrm{NA}]\end{array}$ \\
\hline $\begin{array}{l}>2 \text { risk factors with Framingham } \\
10 \text {-year risk between } 10 \% \text { and } 20 \%\end{array}$ & $\begin{array}{l}\text { Medium } \\
\text { high }\end{array}$ & $\begin{array}{l}<100 \mathrm{mg} / \mathrm{dL} \\
\quad(2.59 \mathrm{mmol} / \mathrm{L})\end{array}$ & $38(3.6)$ & $3(7.9)$ & $\begin{array}{l}\text { Rosuvastatin: } 1(9.1)[\mathrm{NA}] \\
\text { Atorvastatin: } 1(6.2)[\mathrm{NA}] \\
\text { Simvastatin: } 1(20.0)[\mathrm{NA}]\end{array}$ \\
\hline $\begin{array}{l}>2 \text { risk factors with Framingham } \\
10 \text {-year risk }<10 \%\end{array}$ & $\begin{array}{l}\text { Medium } \\
\text { low }\end{array}$ & $\begin{array}{l}<130 \mathrm{mg} / \mathrm{dL} \\
\quad(3.36 \mathrm{mmol} / \mathrm{L})\end{array}$ & $167(16.0)$ & $111(66.5)$ & $\begin{array}{l}\text { Rosuvastatin: } 47(78.2) \\
\quad[\mathrm{NA}] \\
\text { Atorvastatin: } 42(65.6)[\mathrm{NA}] \\
\text { Simvastatin: } 14(51.8)[\mathrm{NA}]\end{array}$ \\
\hline $0-1$ risk factor & Low & $\begin{array}{l}<160 \mathrm{mg} / \mathrm{dL} \\
\quad(4.14 \mathrm{mmol} / \mathrm{L})\end{array}$ & $83(8.0)$ & $59(71.1)$ & $\begin{array}{l}\text { Rosuvastatin: } 27(79.4) \\
\quad[\mathrm{NA}] \\
\text { Atorvastatin: } 18(64.3)[\mathrm{NA}] \\
\text { Simvastatin: } 7(58.3)[\mathrm{NA}]\end{array}$ \\
\hline
\end{tabular}

$C H D$ coronary heart disease, $C V D$ cardiovascular disease, $D B P$ diastolic blood pressure, $H D L-C$ high-density lipoprotein cholesterol, $L D L-C$ low-density lipoprotein cholesterol, NCEP ATP III National Cholesterol Education Program Adult Treatment Panel III, NA not available, SBP systolic blood pressure, $S D$ standard deviation

\section{Results of the Patient Questionnaire}

All of the 1,043 patients available for analysis returned the questionnaire with at least one question completed. Most patients had heard about, or been told about, LDL-C and HDL-C (78.0\% and $70.7 \%$, respectively). The majority (80.6\%) had been informed of their cholesterol levels by their physician, and $76.0 \%$ had been given a target cholesterol level. Additional responses to the patients' questionnaire are shown in Table 6.

\section{Multivariate Analysis of Factors Associated with Achieving LDL-C Treatment Goal}

The main patient and physician factors that were significantly associated with patients 


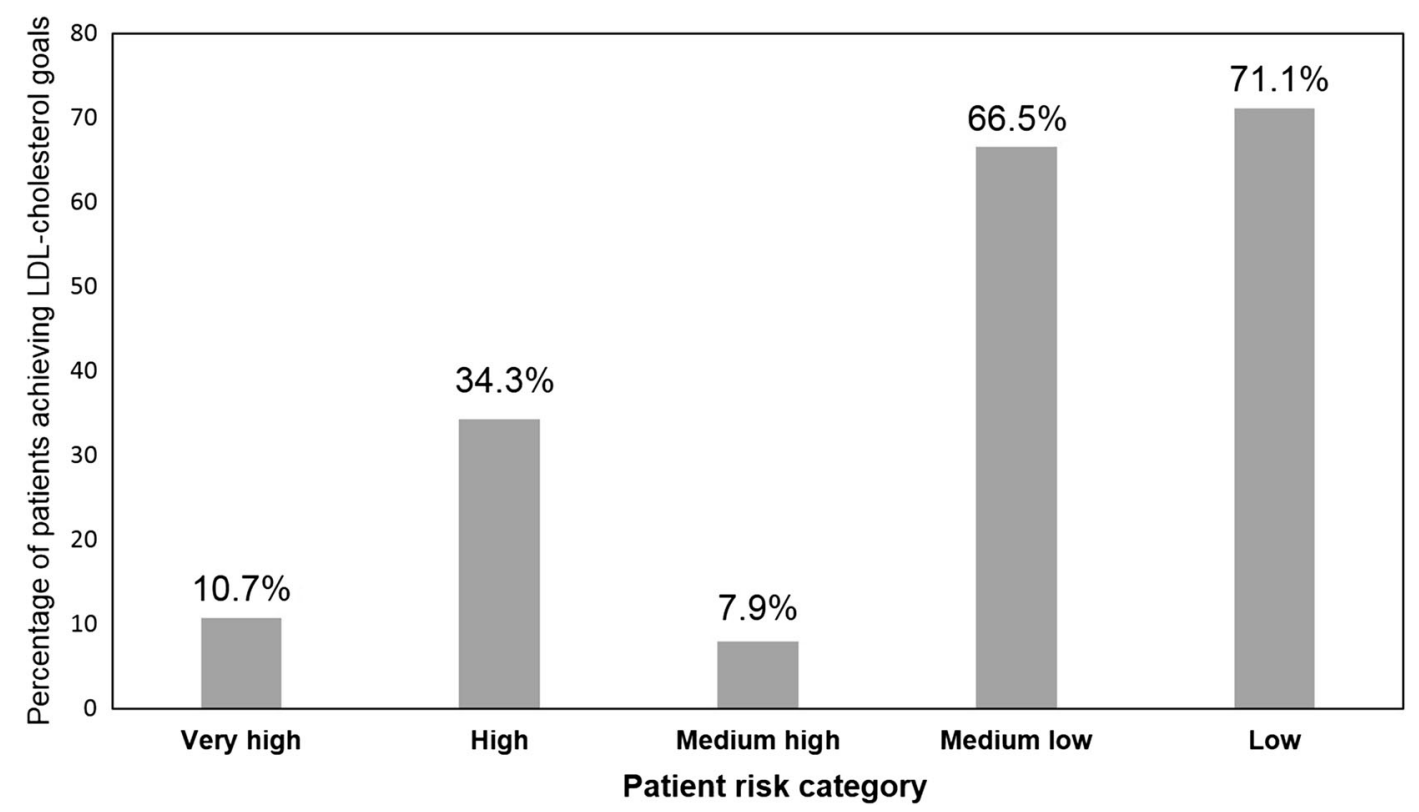

Fig. 1 Patient baseline risk category according to the NCEP ATP III 2004 updated guidelines obtaining their treatment goals. NCEP ATP III US National Cholesterol Education Program Adult Treatment Panel III guidelines

Table 4 Patients achieving LDL-C treatment goals, defined by the NCEP ATP III 2004 updated guideline criteria, depending on risk factors

\begin{tabular}{|c|c|}
\hline Variable & $\begin{array}{l}\text { Patients achieving } \\
\text { treatment goal, } n(\%)\end{array}$ \\
\hline \multicolumn{2}{|c|}{ Patients achieving LDL treatment goal with risk factors } \\
\hline Metabolic syndrome & $132(26.1)$ \\
\hline Current smoker & $34(17.3)$ \\
\hline Diabetes & $104(20.6)$ \\
\hline Arterial hypertension & $192(26.0)$ \\
\hline CVD family history & $112(30.0)$ \\
\hline \multicolumn{2}{|c|}{$\begin{array}{l}\text { CVD cardiovascular disease, } L D L-C \text { low-density } \\
\text { lipoprotein cholesterol, NCEP ATP III National } \\
\text { Cholesterol Education Program Adult Treatment Panel III }\end{array}$} \\
\hline $\begin{array}{l}\text { not attaining th } \\
\text { updated LDL-C } \\
\text { forgetting to take } \\
3.3 ; 95 \% \text { confider } \\
\text { being diabetic (OR } \\
\text { (OR 2.4; CI } 1.6-3 \\
1.8 ; \text { CI } 0.9-3.6 \text { ). }\end{array}$ & $\begin{array}{l}\text { NCEP ATP III } 2004 \\
\text { atment goal were: } \\
\text { lets [odds ratio (OR) } \\
\text { interval (CI) } 1.2-8.6] \text {; } \\
\text { CI 2.0-3.6); smoking } \\
\text { and age <40 years (OR }\end{array}$ \\
\hline
\end{tabular}

\section{DISCUSSION}

The primary aim of this study was to investigate the proportion of patients receiving lipidlowering pharmacological treatment in Egypt who reach their LDL-C treatment goals. Study subjects had already been receiving lipidlowering medications prior to their inclusion. Overall, this study found that the management of patients requiring lipid-lowering therapeutic intervention is moderate to poor in Egypt, with less than $50 \%$ of treated patients achieving the treatment goals stipulated in the NCEP ATP III 2004 updated guidelines. When looking at the success of treatment in patients categorized according to risk, those considered very high risk (who comprised 38\% of the study population) were particularly poorly managed, with only $10 \%$ achieving their treatment goal. In contrast, over $65 \%$ of patients in the low or medium-low risk categories successfully attained their treatment goal, although it should be noted that these combined patient 
Table 5 Responses to the investigators' questionnaire

\begin{tabular}{|c|c|c|c|c|c|}
\hline Question & $\begin{array}{l}\text { Response, } \\
\text { proportion } \\
\text { of } \\
\text { respondents, } \\
\%\end{array}$ & $\begin{array}{l}\text { Response, } \\
\text { proportion of } \\
\text { respondents, \% }\end{array}$ & $\begin{array}{l}\text { Response, } \\
\text { proportion of } \\
\text { respondents, } \\
\%\end{array}$ & $\begin{array}{l}\text { Response, } \\
\text { proportion } \\
\text { of } \\
\text { respondents, } \\
\%\end{array}$ & $\begin{array}{l}\text { Response, } \\
\text { proportion } \\
\text { of } \\
\text { respondents, } \\
\%\end{array}$ \\
\hline $\begin{array}{l}\text { What is the frequency of visits to } \\
\text { review cholesterol levels? }\end{array}$ & Annual, 2.6 & 6 months, 23.4 & 3 months, 68.8 & $\begin{array}{l}\text { More } \\
\text { frequent } \\
\text { than } 3 \\
\text { months, } 5.2\end{array}$ & \\
\hline $\begin{array}{l}\text { What treatment type do you } \\
\text { usually recommend? }\end{array}$ & Statins, 85.9 & Fibrates, 9.2 & $\begin{array}{l}\text { Bile acid } \\
\text { sequestrants, } \\
0.1\end{array}$ & Other, 4.6 & \\
\hline $\begin{array}{l}\text { Which statin do you usually } \\
\text { prescribe? }\end{array}$ & $\begin{array}{l}\text { Atorvastatin, } \\
48.5\end{array}$ & Rosuvastatin, 34.9 & $\begin{array}{l}\text { Simvastatin, } \\
13.7\end{array}$ & Other, 2.9 & \\
\hline $\begin{array}{l}\text { 'A sufficient number of patients } \\
\text { reach their target LDL } \\
\text { cholesterol levels' }\end{array}$ & $\begin{array}{l}\text { Strongly } \\
\text { agree, } 21.3\end{array}$ & Agree, 45.3 & $\begin{array}{l}\text { Neither agree } \\
\text { nor disagree, } \\
22.7\end{array}$ & Disagree, 8.0 & $\begin{array}{l}\text { Strongly } \\
\text { disagree, } 2.7\end{array}$ \\
\hline $\begin{array}{l}\text { What percentages of those that } \\
\text { have been set a target cholesterol } \\
\text { level fall into the following } \\
\text { categories? }\end{array}$ & $\begin{array}{l}\text { Reached and } \\
\text { sustained } \\
\text { target level, } \\
45.4\end{array}$ & $\begin{array}{l}\text { Generally stay at } \\
\text { target level, } \\
\text { occasionally too } \\
\text { high, } 23.9\end{array}$ & $\begin{array}{l}\text { Previously } \\
\text { reached target } \\
\text { level, now } \\
\text { lapsed, } 20.5\end{array}$ & $\begin{array}{l}\text { Have never } \\
\text { reached } \\
\text { target level, } \\
11.7\end{array}$ & \\
\hline
\end{tabular}

groups only accounted for a quarter of the study population; most study participants were in the very high and high-risk categories (72.4\%).

These findings conflict with the result that most investigators (74\%) stated that they used guidelines to establish individual target cholesterol levels for patients, most commonly the NCEP ATP III 2004 updated guidelines. The findings are also in contrast to the beliefs of the treating physicians, as more than $60 \%$ of investigators either agreed or strongly agreed with the statement that they felt a sufficient number of patients reached their target levels. However, the finding is more in line with patient perception, as only around 50\% of patients stated that they were satisfied with their treatment.
Evaluation of sub-groups of patients with established risk factors for CVD showed that hypercholesterolemia was particularly poorly managed in patients who were current smokers $(18.9 \%$ of participants) or were diabetic ( $48.5 \%$ of participants), whereas only $17.3 \%$ and $20.6 \%$ of patients, respectively, attained their NCEP ATP III 2004 updated LDL-C treatment goal. Patients with metabolic syndrome, arterial hypertension or a family history of CVD, $30 \%$ or less were successfully treated.

The majority of patients in this study (85.9\%) were prescribed statins, which are well established as an effective treatment of dyslipidemia $[15,16]$. The most commonly prescribed statins were atorvastatin and 
Table 6 Responses to the patients' questionnaire

\begin{tabular}{|c|c|c|c|c|c|}
\hline Question & $\begin{array}{l}\text { Response, } \\
\text { proportion of } \\
\text { respondents, } \\
\%\end{array}$ & $\begin{array}{l}\text { Response, } \\
\text { proportion of } \\
\text { respondents, } \\
\%\end{array}$ & $\begin{array}{l}\text { Response, } \\
\text { proportion of } \\
\text { respondents, } \\
\%\end{array}$ & $\begin{array}{l}\text { Response, } \\
\text { proportion of } \\
\text { respondents, \% }\end{array}$ & $\begin{array}{l}\text { Response, } \\
\text { proportion of } \\
\text { respondents, } \\
\%\end{array}$ \\
\hline $\begin{array}{l}\text { How many times has your } \\
\text { medication changed since } \\
\text { initiation? }\end{array}$ & Zero, 69.9 & $\begin{array}{l}\text { Same } \\
\text { medication, } \\
\text { changed dose, } \\
8.4\end{array}$ & $\begin{array}{l}\text { Once or twice, } \\
16.9\end{array}$ & Several times, 3.4 & No answer, 1.4 \\
\hline $\begin{array}{l}\text { Do you feel any of the following } \\
\text { about the way your high } \\
\text { cholesterol has been treated? }\end{array}$ & Satisfied, 50.0 & $\begin{array}{l}\text { Motivated, } \\
36.9\end{array}$ & $\begin{array}{l}\text { Concerned, } \\
22.4\end{array}$ & $\begin{array}{l}\text { Frustrated, } \\
\text { disappointed, } \\
\text { or confused, } \\
14.5\end{array}$ & $\begin{array}{l}\text { No strong } \\
\text { feelings, } 24.7\end{array}$ \\
\hline $\begin{array}{l}\text { How often do you forget to take } \\
\text { your medication? }\end{array}$ & $\begin{array}{l}\text { More than } \\
\text { once a week, } \\
12.3\end{array}$ & $\begin{array}{l}\text { Once every } \\
2 \text { weeks, } 11.0\end{array}$ & $\begin{array}{l}\text { Once a week, } \\
18.5\end{array}$ & $\begin{array}{l}\text { Once a month } \\
\text { or less, } 16.4\end{array}$ & $\begin{array}{l}\text { No answer, } \\
41.7\end{array}$ \\
\hline $\begin{array}{l}\text { How often do you think you } \\
\text { can miss a dose without } \\
\text { affecting your cholesterol } \\
\text { levels? }\end{array}$ & $\begin{array}{l}\text { More than } \\
\text { once a week, } \\
15.2\end{array}$ & $\begin{array}{l}\text { Once every } \\
2 \text { weeks, } 13.0\end{array}$ & $\begin{array}{l}\text { Once a week, } \\
27.6\end{array}$ & $\begin{array}{l}\text { Once a month } \\
\text { or less, } 41.4\end{array}$ & No answer, 2.8 \\
\hline
\end{tabular}

Table 7 Overall proportion of patients achieving LDL-C target levels in CEPHEUS studies

\begin{tabular}{ll}
\hline Country/region & $\begin{array}{l}\text { Overall proportion } \\
\text { achieving LDL-C target, \% }\end{array}$ \\
\hline Egypt (this study) & 32.5 \\
Middle East [17] & 52.0 \\
Western Europe [20] & 57.4 \\
Greece [19] & 49.3 \\
South Africa [18] & 60.5 \\
Asia [21] & 49.1 \\
Hong Kong [22] & 82.9 \\
\hline
\end{tabular}

CEPHEUS Centralized Pan-Middle East Survey on the under-treatment of hypercholesterolemia, $L C L-C$ lowdensity lipoprotein cholesterol

rosuvastatin, prescribed for $48.9 \%$ and $34.9 \%$, respectively, of those patients receiving statins. The most effective statins according to this study were rosuvastatin, pravastatin and simvastatin, with $39.0,37.5$ and $33.8 \%$ of patients who were prescribed these medications achieving their LDL-C treatment goals, respectively. It should be remembered that the number of patients in the lower risk categories was low, and some of the most favorable results were observed in patients categorized according to the NCEP ATP III 2004 updated guidelines as medium or low risk who were treated with rosuvastatin. In these sub-groups of patients, $>70 \%$ of patients were successfully treated.

Results of the patient questionnaire reported that most patients (>80\%) had not changed their medication from their initial treatment recommendation at diagnosis, and less than $10 \%$ had received a dose increase. This finding could suggest that failure of treating physicians to adapt an individual's response to treatment may be a factor in the overall failure of patients 
to be successfully managed for hypercholesterolemia.

Patient compliance to treatment is another factor that could influence treatment outcomes. In this study, $12 \%$ of patients admitted forgetting to take their prescribed medication more than once a week, and $16 \%$ stated that they forgot no more than once a month. Furthermore, in the multivariate analysis, forgetting to take tablets was strongly correlated with not attaining treatment goals.

A report of the CEPHEUS study in six Middle Eastern countries (Bahrain, Oman, Qatar, UAE, KSA and Kuwait), concluded that hypercholesterolemia was sub-optimally managed across these countries, particularly in those with a high or very high risk of a cardiovascular event [17]. In the overall regional analysis, $52 \%$ of patients attained their LDL-C treatment goal, as defined by the NCEP ATP III 2004 updated guidelines. The results reported here of the Egyptian arm of the CEPHEUS study show that management of hypercholesterolemia in Egypt is comparatively worse than the average for other similar countries in the region. Results of other arms of the CEPHEUS study commonly report that hypercholesterolemia is successfully treated in only approximately 50\% of cases (Table 7). The individual results for the proportion of patients achieving their NCEP ATP III 2004 updated guideline-defined treatment goal are: $52 \%$ for South Africa, $49 \%$ for Greece, $57 \%$ for combined western European countries and $49 \%$ for combined Asian countries [18-21]. These results are in contrast to other regions of the world, where studies have reported that the majority of patients actively treated for hypercholesterolemia achieve their treatment goals. For example, in Hong Kong, 83\% of the participants in the CEPHEUS study achieved their treatment goal, and the Lipid treatment assessment project 2 (L-TAP2) study, conducted in nine countries in Europe, North America and Asia, found the attainment rate was $73 \%$ in these countries [22, 23]. Similarly, concerning findings were also reported for the INTERHEART study, conducted between 1999 and 2003, which found that less than $5 \%$ of patients admitted for their first AMI in the Middle East were taking any lipid-lowering medications (primary prevention), and this only increased to $50 \%$ upon discharge (secondary prevention) [3].

This study was an observational rather than interventional study, and as such it suffers from a number of limitations. There are likely to be differences in clinical practice between study sites, and this was not accounted for in the combined analysis of the data. Furthermore, the study population comprised only those patients being actively treated with lipid-lowering medication, and the proportion of eligible patients with risk factors for CVD being actively treated was not ascertained. In addition, data on lifestyle factors or socioeconomic status were not collected and, therefore, not considered in the analysis. These combined factors should be taken into consideration when evaluating the findings.

At the time of conducting the study (2010-2011), most physicians treated patients according to the NCEP ATP III 2004 updated guidelines. Since the end of the study, updated guidance from the American College of Cardiology and American Heart Association has concluded that there was insufficient evidence to support the continued use of LDL$C$ or non-HDL-C treatment targets, instead recommending different intensities of statin treatment for patients based on four statin benefit groups [24]. While it would be interesting to apply the updated guidance to 
the results of this study, due to the enrolment criterion of patients already receiving lipidlowering drugs for at least 3 months there are no baseline measurements against which to compare. Additionally, resource limitations prevent us from re-classifying patients into the revised risk groups to perform re-analyses against the latest guidance, or from providing additional statistical analyses on comparisons between risk groups.

\section{CONCLUSION}

In conclusion, this study found that hypercholesterolemia is not being effectively managed in many at-risk patients in Egypt. The majority of patients enrolled in the study, all of whom were being actively treated with lipidlowering medication, were considered at high risk of a cardiovascular event, and hypercholesterolemia was particularly poorly managed in this group. Initiatives to improve physicians' management of these patients and patient compliance to treatment are urgently needed.

\section{ACKNOWLEDGMENTS}

Sponsorship for this study and article processing charges were provided by an unrestricted research grant from AstraZeneca, Cairo, Egypt. All authors had full access to all of the data in this study and take complete responsibility for the integrity of the data and accuracy of the data analysis. Editorial assistance for the development of the manuscript was provided by Dr Debra Scates and Dr Toby Galbraith of IMC Healthcare Communication, London, UK, supported by AstraZeneca Egypt. All named authors meet the ICMJE criteria for authorship for this manuscript, take responsibility for the integrity of the work as a whole and have given final approval for the version to be published.

Conflict of interest. A. Reda, A. A. AbdelRehim, A. Etman and O. S. A. Afifi declare no conflict of interest.

Compliance with ethics guidelines. All procedures followed were in accordance with the ethical standards of the responsible committee on human experimentation (institutional and national) and with the Helsinki Declaration of 1975 , as revised in 2000 and 2008. Informed consent was obtained from all patients for being included in the study.

Author contributions. A. Reda is the principal investigator of this study and provided data interpretation and critical revision of article. A. A. Abdel-Rehim provided the study concept and design, and analyzed the data for diabetic sub-groups. A. Etman provided study concept, design and data interpretation. O. S. A. Afifi provided data interpretation and critical revision of article.

Open Access. This article is distributed under the terms of the Creative Commons Attribution Noncommercial License which permits any noncommercial use, distribution, and reproduction in any medium, provided the original author(s) and the source are credited.

\section{REFERENCES}

1. World Health Organization. Global status report on noncommunicable diseases 2010. Geneva: WHO; 2011. http://www.who.int/nmh/publications/ncd report_full_en.pdf. Accessed Oct 30, 2014.

2. Mathers CD, Loncar D. Projections of global mortality and burden of disease from 2002 to 2030. PLoS Med. 2006;3:e442. 
3. Gehani AA, Al-Hinai AT, Zubaid M, INTERHEART Investigators in Middle East, et al. Association of risk factors with acute myocardial infarction in Middle Eastern countries: the INTERHEART Middle East study. Eur J Prev Cardiol. 2014;21:400-10.

4. Yusuf S, Hawken S, Ounpuu S, INTERHEART Study Investigators, et al. Effect of potentially modifiable risk factors associated with myocardial infarction in 52 countries (the INTERHEART study): case-control study. Lancet. 2004;364:937-52.

5. Almahmeed W, Arnaout MS, Chettaoui R, et al. Coronary artery disease in Africa and the Middle East. Ther Clin Risk Manag. 2012;8:65-72.

6. Alberti KG, Zimmet P, Shaw J, IDF Epidemiology Task Force Consensus Group. The metabolic syndrome-a new worldwide definition. Lancet. 2005;366:1059-62.

7. Law MR, Wald NJ, Thompson SG. By how much and how quickly does reduction in serum cholesterol concentration lower risk of ischaemic heart disease? BMJ. 1994;308:367-72.

8. Law MR, Wald NJ, Rudnicka AR. Quantifying effect of statins on low density lipoprotein cholesterol, ischaemic heart disease, and stroke: systematic review and meta-analysis. BMJ. 2003;326:1423.

9. Law MR, Wald NJ. An ecological study of serum cholesterol and ischaemic heart disease between 1950 and 1990. Eur J Clin Nutr. 1994;48:305-25.

10. Program National Cholesterol Education (NCEP) Expert Panel on Detection, Evaluation, and Treatment of High Blood Cholesterol in Adults (Adult Treatment Panel III). Third Report of the National Cholesterol Education Program (NCEP) Expert Panel on Detection, Evaluation, and Treatment of High Blood Cholesterol in Adults (Adult Treatment Panel III): final report. Circulation. 2002;106:3143-421.

11. The Long-Term Intervention with Pravastatin in Ischaemic Disease (LIPID) Study Group. Prevention of cardiovascular events and death with pravastatin in patients with coronary heart disease and a broad range of initial cholesterol levels. $\mathrm{N}$ Engl J Med. 1998;339:1349-57.

12. LaRosa JC, He J, Vupputuri S. Effect of statins on risk of coronary disease: a meta-analysis of randomized controlled trials. JAMA. 1999;282:2340-6.

13. Alter DA, Manuel DG, Gunraj N, Anderson G, Naylor CD, Laupacis A. Age, risk-benefit trade-offs, and the projected effects of evidence-based therapies. Am J Med. 2004;116:540-5.
14. Grundy SM, Cleeman JI, Merz CN, National Heart, Lung, and Blood Institute; American College of Cardiology Foundation; American Heart Association, et al. Implications of recent clinical trials for the National Cholesterol Education Program Adult Treatment Panel III guidelines. Circulation. 2004;110:227-39.

15. The Scandinavian Simvastatin Survival Study Group. Randomised trial of cholesterol lowering in 4,444 patients with coronary heart disease: the Scandinavian Simvastatin Survival Study (4S). Lancet. 1994;344:1383-9.

16. Downs JR, Clearfield $M$, Weis $S$, et al. Primary prevention of acute coronary events with lovastatin in men and women with average cholesterol levels: results of AFCAPS/TexCAPS. Air Force/Texas Coronary Atherosclerosis Prevention Study. JAMA. 1998;279:1615-22.

17. Arafah M, Al-Hinai AT, Mahmeed WA, et al. Centralized Pan-Middle East survey on the undertreatment of hypercholesterolemia: results from the CEPHEUS study in Arabian Gulf countries. Angiology. 2014;65:919-26.

18. Raal F, Schamroth C, Blom D, et al. CEPHEUS SA: a South African survey on the under-treatment of hypercholesterolaemia. Cardiovasc J Afr. 2011;22:234-40.

19. Elisaf MS, Nikas N. Centralized Pan-European survey on the undertreatment of hypercholesterolemia in patients using lipid lowering drugs-the CEPHEUS-Greece survey. Angiology. 2010;61:465-74.

20. Hermans MP, Castro Cabezas M, Strandberg T, et al. Centralized Pan-European survey on the undertreatment of hypercholesterolaemia (CEPHEUS): overall findings from eight countries. Curr Med Res Opin. 2010;26:445-54.

21. Park JE, Chiang CE, Munawar M, et al. Lipidlowering treatment in hypercholesterolaemic patients: the CEPHEUS Pan-Asian survey. Eur J Prev Cardiol. 2012;19:781-94.

22. Chan RH, Chan PH, Chan KK, et al. The CEPHEUS Pan-Asian survey: high low-density lipoprotein cholesterol goal attainment rate among hypercholesterolaemic patients undergoing lipidlowering treatment in a Hong Kong regional centre. Hong Kong Med J. 2012;18:395-406.

23. Waters DD, Brotons C, Chiang CW, Lipid Treatment Assessment Project 2 Investigators, et al. Lipid treatment assessment project 2: a multinational survey to evaluate the proportion of patients achieving low-density lipoprotein cholesterol goals. Circulation. 2009;120:28-34. 
24. Stone NJ, Robinson JG, Lechtenstein AH, American College of Cardiology/American Heart Association Task Force on Practice Guidelines, et al. 2013 ACC/ AHA guideline on the treatment of blood cholesterol to reduce atherosclerotic cardiovascular risk in adults. J Am Coll Cardiol. 2014;63:2889-934. 